\title{
Getting to know each other: Integrating radiation and medical oncology training in urology (and urology training in oncology)
}

\author{
Keith Rourke, MD, FRCSC \\ Division of Urology, Department of Surgery, University of Alberta, Edmonton, AB, Canada
}

Cite as: Can Urol Assoc J 2018;12(10):326-7. http://dx.doi.org/10.5489/cuaj.5607

See related article on page 321

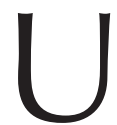
rology is both a surgical and medical discipline and as a consequence we have always been actively involved in the medical treatment of our diseases. Additionally, oncology, in some form or another, constitutes a large part of urological practice and training. Over the last decade, there has been an explosion in medical advances in advanced urological malignancy, particularly prostate and renal. ${ }^{1-3}$ While radiation and medical oncologists are undoubtedly the physicians most skilled at administering radiation and chemotherapy, respectively, patients with advanced urological malignancy most often present to a urologist first. Thus, it is the urologist who most often provides the initial treatment recommendations and, as a consequence, what a urologist recommends is most often what the patient decides. ${ }^{4}$ Based on these factors, it makes "evolutionary" sense that a growing number of urologists have added chemotherapy to their therapeutic repertoire. It then seems logical to further enhance radiation and medical oncology training in our urology residency programs.

In this edition of CUAJ, Taggar et al surveyed 32\% ( $n=60)$ of our current or recent urology residents regarding their didactic and clinical training experiences in both radiation and medical oncology. ${ }^{5}$ The authors identified a potential unmet need in radiation and medical oncology training in urology. This finding, in turn, begs the question, "What is the best way to incorporate radiation and medical oncology principles into urological residency training?"

Some possible solutions include didactic teaching during academic half-day (AHD), attendance at interprofessional tumour rounds, multidisciplinary clinics, or mandatory clinical rotations. The Royal College of Physicians and Surgeons of Canada (RCPSC) broadly states that all urology training programs must provide "instruction in interdisciplinary oncology to provide residents with a clear understanding of the respective roles of surgery, radiation therapy, chemotherapy, hormonal, and immunotherapy. ${ }^{\prime 6}$ Specific participation in radiation and medical oncology clinics remains optional. Currently, the majority of urological teaching in radiation and medical oncology is provided either during AHD or informal instruction during urology clinics. Despite AHD constituting the majority of radiation and medical oncology exposure, only $61 \%$ and $51 \%$ of residents answered that they had structured didactic teaching in radiotherapy and chemotherapy, respectively. This is likely not sufficient to prepare our trainees for future practice.

In addition to didactic instruction, participation in interprofessional rounds, such as tumour boards, is a RCPSCrecommended training experience in urology. ${ }^{6}$ However, no consensus exists on the required number of rounds a resident should attend. Resident experience in this area appears to be suboptimal, as $56 \%$ of respondents state that they attended less than 10 tumour board conferences per year. Thus, it seems tumour boards, despite being recommended, may also fall short of adequately preparing our residents for clinical practice.

While, $29 \%$ and $41 \%$ of urology residents had mandatory rotations in radiation and medical oncology, respectively, it is likely that urological experience is also lacking in radiation and medical oncology training. Urology (or surgery) is not required, recommended, or even optional in their respective Royal College training documents. It appears that our deficits in training might be a "two-way street," as I would imagine the majority of trainees in radiation or medical oncology have not actively been involved with surgical care of patients since medical school.

To address these shared deficits, implementation of multidisciplinary care clinics is certainly an option that would provide cross-pollination of information between our disciplines. While a dedicated team of physicians is always in the best interest of the patient, it can often be difficult to incorporate this type of clinic into training. Thus, as the medical treatment of urological disease continues to march forward, it would behoove us to implement formal clinical rotations in medical and radiation oncology into our residency programs. After all, $90 \%$ of our residents prefer this, and I'm sure our medical and radiation oncology colleagues 
would cherish the opportunity to get to know us and our trainees better.

Competing interests: Dr. Rourke reports no competing personal or financial interests.

\section{References}

1. Scher HI, Fizazi K, Saad F, et al. Increased survival with enzalutamide in prostate cancer after chemotherapy. N Eng J Med 2012;367:1187-97. https://doi.org/10.1056/NEJMoal 207506

2. de Bono IS, Logothetis $\mathrm{CJ}$, Molina A, et al. Abiraterone and increased survival in metastatic prostate cancer. N Engl J Med 2011;364:1995-2005. https://doi.org/10.1056/NEJMoa1014618

3. Rini BI, Campbell SE. The evolving role of surgery for advanced renal cell cancer in the era of molecular targeted therapy. J Urol 2007;177:1978-84. https://doi.org/10.1016/i.juro.2007.01.136
4. Scherr KA, Fagerlin A, Hofer T, et al. Physician recommendations trump patient preferences in prostate cancer treatment decisions. Med Decis Making 2017;37:56-69. https://doi. org/10.1177/0272989X16662841

5. Taggar AS, Martell K, Husain $S$, et al. Exposure to radiation and medical oncology training: A survey of Canadian urology residents and fellows. Can Urol Assoc J 2018 May 28; Epub ahead of print. https://doi.org/10.5489/cuai.5147

6. Royalcollege.ca. Ottawa: Information by Specialty or Subspecialty; Specific Standards of Accreditation for Residency Programs and Training Experiences [updated July 1, 2018]. Available at http://www.royalcollege.ca/rc/faces/oracle/webcenter/portalapp/pages/ibd. jspx;isessi onid=xXxdMIcrKKbF40BVRMI8mlg0pZapAp34TycH9Jfckr9FW6CECnPY!-424176029?_afrLoop $=44636917417185702 \&$ afrWindowMode=0\&_afrWindowld=null\#! $\% 40 \% 40 \% 3 F$ afrWindowld\%3Dnull\%26 afrLoop\%3D44636917417185702\%26 afrWindowMode\%3D0\%26 adf. ctrl-state\%3D18yrf33n4x_4. Accessed Aug. 21, 2018.

Correspondence: Dr. Keith Rourke, Division of Urology, Department of Surgery, University of Alberta, Edmonton, AB, Canada; krourke@ualberta.ca

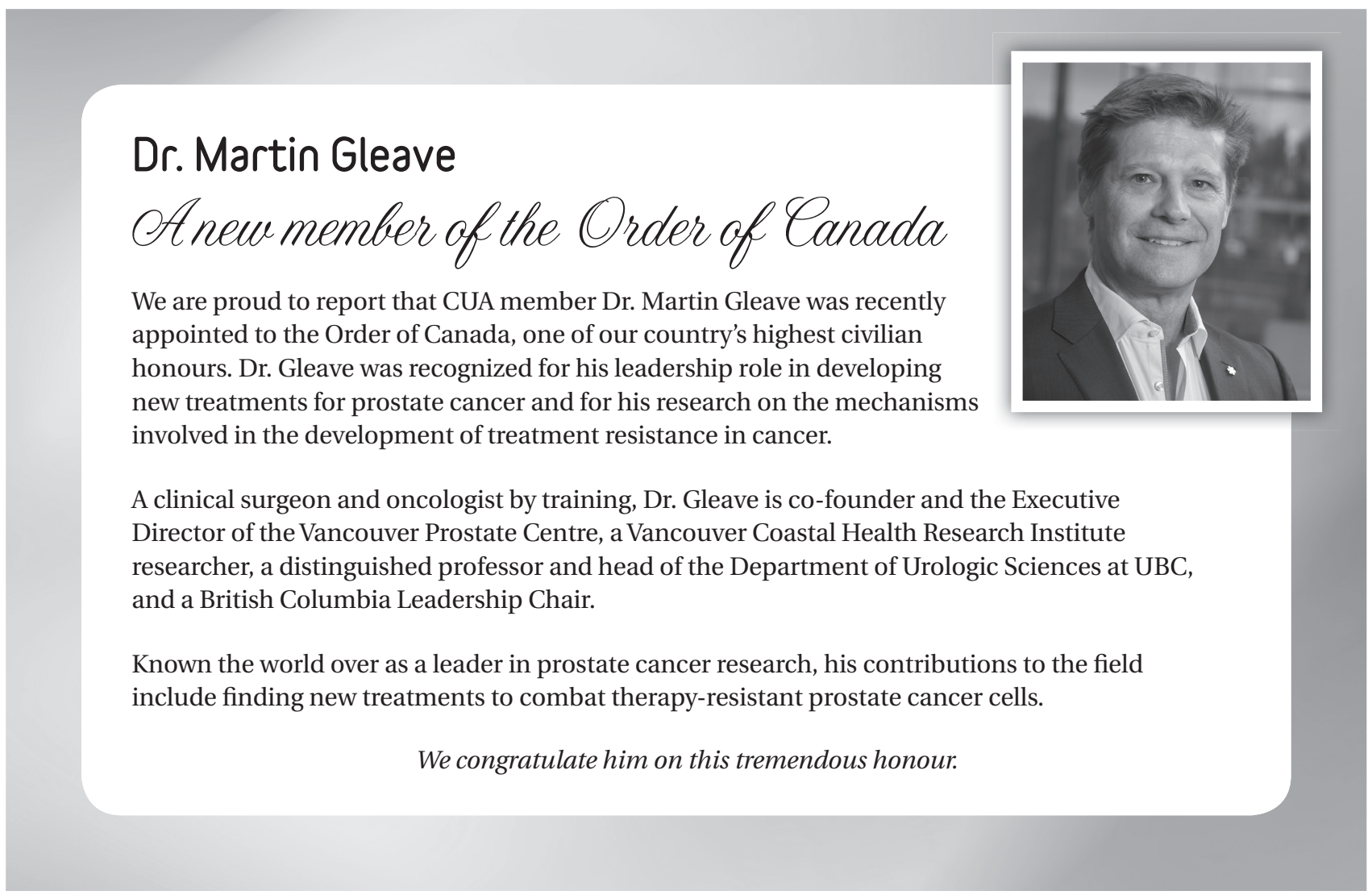

